\title{
Nietzsche-Wagner: Preeminencia de la poesía en la obra de arte total ${ }^{*}$
}

\author{
Nietzsche-Wagner: Pre-eminence of poetry in the total work of art
}

\section{Gonzalo Portales}

Universidad Austral de Chile, Facultad de Filosofía y Humanidades, Instituto de Filosofía y Estudios Educacionales, Valdivia, Chile. Correo electrónico: gportale@uach.cl

El artículo se refiere a la crítica al concepto de obra de arte total (Gesamtkunstwerk) en la estética wagneriana realizada por Nietzsche en su obra tardía. El análisis se desarrolla a partir de la génesis de dicho concepto artístico y su fundamentación en la antigüedad clásica, pasando por los elementos de su composición -poesía, teatro y música- y la pretendida preeminencia del texto poético, hasta culminar en sus efectos sobre la modernidad, especialmente en lo que dice relación con la discusión sobre la industria cultural.

Palabras clave: Nietzsche, Wagner, poesía, obra de arte.

This article examines Nietzsche's criticism to the concept of Gesamtkunstwerk - total work of art - within the Wagnerian aesthetics and considers its impact upon modernity. It begins from the Classical genesis of this artistic concept, then considers the elements of its composition - poetry, theatre, music, - and the supposed pre-eminence of the poetic text, and finally ends with a debate on the consequences to modernity, especially in relation to the Cultural Industry.

Key words: Nietzsche, Wagner, poetry, work of art.

Si se examina la extensa reflexión teórica llevada a cabo por el propio Richard Wagner en torno a su obra artística y se presta suficiente atención a los constantes comentarios autobiográficos que dan cuenta -de manera mitificada, por cierto- de los diversos momentos presentes en la consolidación de sus conceptos fundamentales, se podrá observar que la noción básica de su ideal estético atraviesa y modela desde el comienzo toda su producción.

Entre la serie de escritos wagnerianos dedicados a esta cuestión he privilegiado aquí para el análisis aquellos que claramente se relacionan con la recepción y crítica producidas por el último Nietzsche en los textos que se inscriben en el proyecto tardío de una filosofía del nihilismo europeo. De esta manera, parece conveniente destacar, aunque sólo sea

* $\quad$ Este trabajo es un resultado parcial del proyecto Fondecyt $N^{\circ} 1090379$. 
ejemplarmente en el limitado contexto de este trabajo, no sólo las tesis desarrolladas en el tratado Oper und Drama de 1852, sino también algunos de los aspectos centrales de los ensayos Die Kunst und die Revolution y Das Kunstwerk der Zukunft (ambas de 1849), especialmente en lo que se refiere a los motivos político-culturales inherentes a la percepción de Wagner sobre los fundamentos del vínculo entre arte y pueblo (Volk) -desarrollados en los dos artículos-, y a los parágrafos del segundo acápite de La obra de arte del futuro dedicados a aquello que Wagner entiende como los elementos originales del hombre artístico (der Künstlerische Mensch) y que describe en la trilogía compuesta por la danza (Tanzkunst), la tonalidad musical (Tonkunst) y la poesía (Dichtkunst). ${ }^{1}$

Aun cuando para una mirada contemporánea podría parecer algo sorprendente, se debe confirmar, sin embargo, el hecho de que estas consideraciones acerca del futuro del arte y de su relación con la política se suscitan a partir de una reflexión sobre los acontecimientos revolucionarios de 1848 en Europa y, especialmente, sobre aquellos que se produjeron en la ciudad de Dresde y que provocaron la necesaria huida de Wagner al exilio. Entonces fue identificado por las autoridades policíacas como un revolucionario que habría ejercido cierto protagonismo en los hechos de violencia política y como un cercano a Michail Bakunin, por lo tanto, a las ideas del anarquismo. ${ }^{2}$

Pero la manera como estos escritos interpretan las consecuencias del carácter popular de los levantamientos democrático-burgueses europeos de mediados del siglo XIX, especialmente de la revolución de marzo en Alemania o, dicho con más precisión, en el territorio geopolítico de aquello que desde el Wiener Kongress de 1815 y hasta el año 1866 se denominara Deutscher Bund, merece, sin duda, una consideración particular. Aunque los diversos intentos que "en las últimas décadas" han buscado determinar con exactitud la real influencia que pudo haber tenido el pensamiento de Herder en la génesis del concepto wagneriano de pueblo hayan puesto de manifiesto, sin que ello hubiese sido su propósito, que dicha relación expresa más bien un objeto polémico que una aclaración histórica convincente ${ }^{3}$, no parece desmedido, sin embargo, reconocer sin reservas la existencia de un cierto pathos común entre las ideas políticas y estéticas post-revolucionarias de Wagner y la exaltación prometeica del pueblo en la explicación de la génesis de la creación artística por parte del romanticismo incipiente del Sturm und Drang. El fino trabajo de recepción crítica y de sistematización literaria de tradicionales canciones populares (Volkslieder) realizado por Herder -labor que había adquirido una gran celebridad mediante la edición de los poemas atribuidos a Ossian, supuestamente provenientes

Me parece que ya en esto intentos tempranos se puede percibir aquello que se consolidará en el texto de Oper und Drama y que otorgará contenido al concepto central de toda la estética wagneriana, me refiero a la noción de Gesamtkunstwerk u obra de arte total. La célebre expresión, usada probablemente por primera vez en la obra Ästhetik oder Lehre von Weltanschauung und Kunst (1827) de K.F.E. Trahndorff e inspirada en la reflexión estética del entorno romántico en que se produce la recepción de la filosofía de Schelling, fue apropiada a mediados del siglo por Richard Wagner con el fin de designar, como bien señala Adorno (1997: v. 13, 92) el "drama del futuro" en el que se reúnen elementos poéticos, musicales y mímicos.

2 Cf. Richard Wagner: Mein Leben, (398 y ss). Ciertamente la autobiografía de Wagner relata los hechos desde una distancia que es imposible que la hubiese mantenido en los tiempos en que transcurrieron los acontecimientos revolucionarios, de tal manera que en el texto tardío enfatiza extemporáneamente sus grandes diferencias con Bakunin. Creo que efectivamente las tenía y que éstas eran profundas, pero no por las mismas razones que aduce Wagner cuando cuenta su vida.

3 Cf. Sobre esta posturas en torno a la recepción wagneriana de Herder, revisar principalmente Reckow (1977), Köhler (1996) y Stollberg (2006). 
de la antigua mitología escocesa y cuyos manuscritos se encontrarían en lengua gaélica-, señala con entusiasmo el inicio de una nueva valoración de la creatividad popular, la que es paulatinamente instituida por la crítica romántica como el criterio fundamental para reconocer el carácter genuino y original de una obra poética. ${ }^{4}$

Parece simple constatar que las obras tempranas de Wagner referidas al proceso creativo no se encontraban ajenas a esta tradición y que su extraordinaria pasión por la saga de los Nibelungos y su procedencia anónima respondía asimismo, en gran medida, a este explícito protagonismo del pueblo en la autoría de la obra de arte. Se puede destacar además, a mi juicio, otro manifiesto encuentro entre el objetivo teórico wagneriano y las indagaciones de etnografía cultural emprendidas por Herder cuando se observa el común apremio que los lleva a compartir el culto a la genialidad y, más precisamente aún, a determinar el momento histórico contemporáneo -cada cual en su época- como la necesidad de fundar la realización artística en aquello que ambos han coincidido también en denominar Genie der Nation. ${ }^{5}$ Para la estética moderna, se constata, ya no puede ser efectiva la medida canónica de la Poética de Aristóteles y su severidad reglamentaria -válida solamente, según Herder, en relación a los poetas trágicos y comediantes de la antigüedad mediterránea- sino que el nuevo paradigma del acto creador en que se expresa la genialidad arraigada en las culturas de las naciones septentrionales debe ser buscado más bien en los presupuestos estéticos capaces de fundamentar una obra como la de Shakespeare, autor que Wagner equipara a su vez con el artista que "poetiza a partir de la naturaleza íntima y verdadera del pueblo (aus der innigsten, wahrhaftesten Natur des Volkes heraus dichtete Shakespeare...)”, razón por la que le habría sido posible comprender cabalmente la estrecha relación entre poesía y música (Nilges 2007, p. 90 y ss). ${ }^{6}$ La modernidad literaria demanda un tipo de juicio que provenga de una poética de la genialidad liberada de los requerimientos normativos de la mímesis y que obsequie espacio a la exaltación creativa aun cuando de este modo se transgredan las leyes de la composición. La obra shakesperiana viene a dirimir así completamente la Querelle des Anciens et des Modernes en lo que se refiere a su versión alemana. Sin embargo, el mismo Wagner comprueba con cierto desasosiego que aquello que Shakespeare representa ya de manera consolidada en la cultura nacional inglesa -mediante la identificación de su arte con el pueblo y su agudeza originaria- no ha sido aún alcanzado por el espíritu germano a causa de una débil estructura política que impide la configuración de una "nación" alemana.

El fracaso de la revolución demanda, pues, a juicio de Wagner, un estudio sobre el actual estado de cosas que tenga presente el contexto histórico europeo de este malogrado devenir en el proceso de constitución del Volk en suelo alemán. Tal consideración lo lleva

\footnotetext{
El ejemplo más célebre de este tipo de interpretación romántica lo constituye, sin duda, el Prolegomena ad Homerum de Friedrich August Wolf, en el que se atribuye una tradición popular rapsódica anterior a la versión escrita de las célebres obras épicas, estableciendo con ello una autoría múltiple proveniente del pueblo. En el caso de este "Homero del norte", como fue llamado Ossian, se ha demostrado incuestionablemente la falsedad de la edición realizada por James Macpherson en el siglo XVIII, aunque Herder defendió hasta el último su autenticidad, cf. Herder: Auszug aus einem Briefwechsel über Ossian und die Lieder alter Völker (1773). Para un contexo más amplio de la recepción de las Volkslieder y para la continuidad de éstas en el romanticismo (Brentano, Tieck y Görres), véase Viktor Žmegač (2001).

5 La expresión proviene de Herder y es recogida por Wagner cuando habla de un dichterische Genie der Nation (t. V, 15).

$6 \quad$ Cf. el artículo sobre Shakespeare de Herder en Von deutscher Art und Kunst (1773) y en Das Kunstwerk der Zukunft el de Wagner (t. III, 108-109).
} 
a retornar hasta lo que cree distinguir como los antecedentes griegos clásicos de esta tradición con el fin de elaborar un diagnóstico del sombrío presente que simultáneamente ofrezca la proyección de un porvenir estético- político a este nuevo artista del futuro (Künstler der Zukunft) formado por el mismo pueblo. Aun cuando es difícil establecer con certeza la cantidad y calidad del conocimiento wagneriano de la antigüedad griega, pues los relatos autobiográficos siguen siendo la principal fuente de testimonio sobre sus lecturas y la información allí contenida es, además, el único origen de la reconstrucción de la así llamada "biblioteca del exilio” (Müller y Panagl 2002), se puede suponer, sin embargo, que Wagner procede en este caso, como en muchos otros, de manera intuitiva y ecléctica, buscando en este pasado clásico elementos cuya apropiación ayude antes que nada al enriquecimiento de sus propias indagaciones, sin detenerse en ello en el examen de pormenores filológicos o en la indagación de verificaciones históricas. Así, no parece necesario examinar aquí y ahora potenciales premisas de sus tesis y menos aún buscar una literatura que pudiese avalar académicamente los contenidos específicos de su interpretación tanto de la épica arcaica como de la literatura trágica ${ }^{7}$, sino que esta recepción debiera ser más bien entendida, por decirlo de alguna manera, como una intervención ejecutada desde determinados fines "intra-wagnerianos" a los que dichas "obras universales” se ordenarían solamente en calidad de medios. Los ejemplos más evidentes de este tipo de asimilación se perciben en el uso de la Orestíada de Esquilo para la elaboración del proyecto temprano de la obra operística Achilleus, como también en la manifiesta alusión en Tannhäuser a la fiesta dionisíaca mediante la bacanal del Venusberg, pero asimismo en numerosas de las caracterizaciones teatrales, donde se expresan los paradigmas griegos de la amistad, del amor fraterno y de los rasgos edípicos de la añoranza materna. Muchas veces también sucede que los acontecimientos dramáticos del universo wagneriano se desencadenan regidos por los vínculos incomprensibles del fatal destino o por el propósito en ocasiones misterioso y vengativo de los mismos dioses olímpicos que parecen renacer así en una época muy distante a la del original politeísmo. ${ }^{8}$

Eximido, pues, de la aplicación de toda crítica histórico filológica en su modo de aproximación a la mitología literario-religiosa de la antigüedad, escribe Wagner al comienzo del ensayo sobre Arte y Revolución: "El espíritu griego, tal como se diera a conocer en la época del florecimiento del Estado y del Arte, encontró en la figura de Apolo al verdadero y principal dios nacional de las tribus helenas, luego de haber superado la tosca religión natural de sus raíces asiáticas y de haber puesto al hombre libre, bello y fuerte en la cúspide de la conciencia religiosa”. Apolo -se permite aún añadir unas líneas más adelante- sería además el "ejecutor de la voluntad de Zeus en la tierra” y se igualaría sin más con el mismo pueblo. "Esto era la obra de arte griega” -concluye el párrafo: “Apolo devenido arte real y vital. Esto era el pueblo griego en su más elevada verdad y belleza” (t.III, 9-11). ${ }^{9}$ Un examen realmente minucioso

Un catastro de algunas de estas lecturas y de las traducciones al alemán de las obras griegas leídas por Wagner se encuentra, no obstante, en la obra Ring und Gral de Ulrich Müller y Oswald Panagl (2002: 127-128).

8 Las alusiones mitológicas o trágicas pueden ser mezcladas por Wagner sin problemas con otras expresiones artísticoculturales, de tal manera que bien se puede advertir un Pathos trágico griego en la composición de un personaje procedente claramente del caballero medieval.

9 "Der griechische Geist, wie er sich zu seiner Blüthezeit in Staat und Kunst zu erkennen gab, fand, nachdem er die rohe Naturreligion der asiatischen Heimath überwunden, und den schönen und starken freien Menschen auf die Spitze seines religiösen Bewußtseins gestellt hatte, seinen entsprechendsten Ausdruck in Apollon, dem eigentlichen Haupt- und Nationalgotte der hellenischen Stämme” (...) Apollon war der Vollstrecker von Zeus’ Willen auf der 
de este pasaje requeriría de un tiempo y un espacio distintos de los que dispone este trabajo, pero incluso a una observación de índole menos rigurosa le está concedido percibir que en esta sui generis indagación de fundamentos para su proposición estética Wagner se siente arrastrado hacia orígenes tan grandiosos como los que se exponen en esta teofanía, en la que la divinidad apolínea es identificada no sólo con el arte (especialmente con el musical, como se sabe), sino también con la obra de arte misma y con el sujeto creador expresado en el pueblo, el que a su vez alcanzaría mediante la actividad artística la cima de la verdad (alétheia) y de la belleza (kalós). Para ello no basta, sin embargo, con el cultivo de un arte particular, sino que se vuelve necesario e imprescindible -tal como lo expresaría el paradigma griego- una armónica asociatividad sincrética de las artes. "En todas partes en que el pueblo ha poetizado”, escribe Wagner, “-y sólo y únicamente se puede poetizar desde el pueblo o en su sentido- se puso también la intención poética en la vida como cabeza del hombre pleno, pero sólo sobre los hombros de la danza y del arte tonal” (t. III, 103).

Una versión más directa y coloquial de esta cuestión se encuentra en una carta enviada por Wagner a Berlioz ${ }^{10}$ con el fin de dar a conocer sus ideas estéticas en el mundo artístico musical parisino y que éste publicara en la prestigiosa revista Journal des Débats, desde la cual fue prontamente recepcionada por Baudelaire como una nueva Lettre sur la musiquee y citada en su ensayo dedicado a la defensa de la obra wagneriana luego de los incidentes que afectaron al estreno de Tannhäuser en París: “Me pregunté” - revela allí Wagner a Berlioz- “cuáles habrían de ser las condiciones del arte para que pudiesen inspirar al público un inviolable respeto y, con el fin de no aventurarme en exceso en el examen de esta cuestión, me fui a buscar el punto de partida a la Grecia antigua. Allí me encontré de entrada con la obra artística por excelencia, el drama, en el cual la idea, por muy profunda que sea, puede manifestarse con la mayor claridad y de la manera más universalmente inteligible. Hoy nos extrañamos con razón de que treinta mil griegos pudieran seguir con sostenido interés la representación de las tragedias de Esquilo"1; pero si buscamos el medio a través del cual se obtenían semejantes resultados, hallamos que es mediante la alianza de todas las artes que concurrían juntas al mismo fin (l'alliance de tous les artes concourant ensemble au même but), es decir, a la producción de la obra artística más perfecta y única auténtica (et la seule vraie). Esto me condujo a estudiar las relaciones de las diversas ramas del arte entre sí, y, tras haber captado la relación que existe entre la

griechischen Erde, er war das griechische Volk (...) "Das war das griechische Kunstwerk, das der zu wirklicher, lebendiger Kunst gewordene Apollon, - das war das griechische Volk in seiner höchsten Wahrheit und Schönheit" (trad. propia).

10 Aun cuando la relación con Berlioz se vio afectada por ciertas expresiones desfavorables de Wagner sobre la Symphonie fantastique, que Robert Schumann hizo públicas en un número de la Neue Zeitschrift für Musik, se puede constatar tanto una comunidad de intereses como también evidentes influencias. No sólo habría que subrayar que el Leitmotiv wagneriano tiene su antecedente en la idée fixe de Berlioz, sino además que la obra Grand Traité d'instrumentation et d'orchestration moderne de 1844, editada al año siguiente en alemán con el título Die Moderne Instrumentation und Orchestration, tuvo una importante influencia en todo el desarrollo de la composición y de la ejecución musical de la obra de Wagner.

11 En la actualidad se calcula más o menos en quince mil espectadores el aforo de un teatro como el ateniense de Dioniso. La cantidad reproducida aquí por Wagner se origina, muy probablemente, en una repetición de lo que Platón escribe en Symposion 175 e, sin advertir, sin embargo, el sarcasmo implícito en el pasaje, pues al decir Sócrates que Agatón había resplandecido ante "treinta mil griegos como testigos", está aludiendo prácticamente a toda la población de ciudadano libres atenienses de la época, por lo que la cifra debe entenderse como una ironía mediante hipérbole. 
plástica y la mímica, examiné la que se halla entre la música y la poesía: de aquel examen brotaron de repente claridades que disiparon completamente la oscuridad que hasta entonces me había tenido desazonado”. ${ }^{12}$

Entre los motivos ocultos -o al menos no explícitamente declarados- de esta exposición histórica que emparenta la génesis del concepto de Gesamtkunstwerk de la estética wagneriana con la tradición griega se encuentra, a mi juicio, también y de manera destacada, el anhelo de una utopía cuyo horizonte indica la persecución de un estadio político-artístico del “pueblo alemán” que pudiese mostrarse a su vez como equivalente a la íntima relación que los estudios clásicos decimonónicos pretendieron descubrir, con un grado de certidumbre hoy controvertible, entre el pathos de la tragedia ática y el ethos de la polis ateniense en la antigüedad.

Tal como se puede constatar por medio de la revisión de las fuentes textuales que componen la esmerada documentación acopiada y publicada por Dieter Borchmeyer y Jörg Salaquarda en Nietzsche und Wagner. Stationen einer epochalen Begegnung I, (1994), tanto en la analogía política con la Grecia arcaica como en el anhelo que busca aproximarse a una proporción artística entre la poiesis trágica y la obra de arte total se trataría de un pensamiento en general compartido por el ideal wagneriano y los ensayos filológico-estéticos del joven Nietzsche. Basta, en este sentido, con observar el "Vorwort an Richard Wagner" de la edición de 1872 de Die Geburt der Tragödie para confirmar estas apreciaciones, pero al mismo tiempo, también parece suficiente echar sólo una mirada al "Versuch einer Selbskritik" que antecede a la edición de 1886 de la misma obra para advertir el camino de la diferencia y del quiebre de esa unidad en la proyección utópica. Esto está expresado, quizás, de manera paradigmática en el cambio de la segunda parte del título original “...en el espíritu de la música”, por el más severo subtítulo de “Grecia y el pesimismo”.

Si se analiza, pues, con más atención este cambio, parece que la separación del camino nietzscheano de aquel itinerario trazado y en gran parte, además, realizado por el mismo Wagner, se habría desencadenado no sólo por causa de la insospechada magnitud adquirida por el machinarius productivo de la empresa wagneriana y sus consecuencias en la institucionalidad cultural de la época -así lo ejemplifican claramente Udo Bermbach (2004) y Jonathan Carr (2007)-, sino que tal rompimiento se habría debido también a las consecuencias políticas del proyecto estético de Bayreuth en los tiempos del nihilismo europeo. En primer término, una investigación de este itinerario permite arribar al convencimiento fundado de que se habría producido por parte de Nietzsche una fuerte distancia con respecto al progresivo entusiasmo de Wagner por la producción de un Kunstwerk dirigido expresamente al Volk alemán -insistencia que se remonta a la experiencia de fracaso de su extrañamiento parisino-, advirtiendo en ello las inevitables adulaciones envueltas en un acto creativo que se encuentra al servicio de un gusto destinado a satisfacer demandas populares en el arte. No me parece suficiente apelar en este punto al tópico del "aristocratismo" nietzscheano para intentar explicar adecuadamente este asunto. Por el contrario, aquí se trataría más bien, según mi opinión, de una rigurosa cuestión de teoría estética en cuyo centro crítico se hallaría por lo demás el concepto mismo de Gesamtkunstwerk. Desde la publicación de la imponente Biografía de Friedrich Nietzsche (1978) de Curt

Citado desde Baudelaire (1923: t. IV, 282-83). La versión alemana de esta carta fue publicada posteriormente en el tomo VII de las Sämtliche Schriften und Dichtungen de Wagner (1912-1914: 82 y ss). 
Paul Janz se ha llamado la atención sobre importantes aspectos críticos contenidos ya en la cuarta de las Intempestivas, titulada "Richard Wagner in Beyreuth", y se ha subrayado la implacable sentencia del Nachlaß -correspondiente a la misma época (KSA 7, 756)- en la que se enjuician severamente los componentes de la obra de arte total, restringiendo no sólo el valor poético-musical de la producción wagneriana, sino reduciendo también el drama escenificado a lo que allí se designa como mera retórica. Aun cuando comparto esta constatación ejemplar de distanciamiento temprano enfatizada por Janz (699 y ss.), pienso, sin embargo, que es más conveniente centrarse principalmente en la obra tardía, pues es en ella donde la crítica a Wagner se sitúa en el exclusivo contexto de una reflexión sobre el arte realizada desde los códigos propios del proyecto de una filosofía del nihilismo europeo.

Me parece que podría ser de utilidad hermenéutica destacar en este entorno analítico un pasaje del Nachlaß (KSA 11, 547) en el que el wagnerismo (Wagnerei) es caracterizado como estupefaciente (als Rausch-mittel), es decir, como un tipo de fármaco cuyo efecto consiste antes que nada en inhibir la sensibilidad y producir al mismo tiempo un bienestar puramente artificial. La metáfora alude, a mi juicio, a la espectacularidad que se habría ido apoderando paulatinamente del proyecto artístico de Bayreuth, el que estaría ya dispuesto a volver cada vez más superfluas sus raíces en la tradición y sería capaz de someterse con cierta docilidad a los cánones del éxito que atestiguarían la innegable grandeza del Gesamtkunstwerk. Efectivamente, es posible verificar que la megalomanía wagneriana -la misma que en el espacio cotidiano se expresa en la inmensa desproporción de un modo de vivir que ya no puede guardar ninguna relación con la realidad de sus finanzas personales-, se deja caracterizar en el ámbito estético mediante una frenética búsqueda de grandeza, reconocimiento y ascenso social que en ocasiones lo conduce a un verdadero delirio gigantomáquico. Observando con agudeza este asunto sostiene Thomas Mann en Leiden und Größe Richard Wagners (1933), conferencia dictada en München justo antes de abandonar la Alemania nacionalsocialista, que "la inmortal crítica nietzcheana a Wagner” habría tomado, por causa de esta misma ostentación de grandeza, la forma de un "panegírico con signos inversos (Panegyrikus mit umgekehrten Vorzeichen).” Por su parte, Adorno (Versuch über Wagner 1937/1952) reúne en una misma herencia interpretativa a Mann y Nietzsche en la medida en que les reconoce el origen de la caracterización de tal modo de operar como el actuar propio de un diletante. Adorno acuñará -a partir de estas indicaciones- la expresión de diletantismo monumentalizado -Nietzsche lo califica de diletantismo insolente (KSA 6, 42)- para determinar el arte wagneriano, insistiendo en que ya la misma idea de fusión de las artes en el Gesamtkunstwerk se construye sobre estas bases eclécticas (Adorno 1997: t. 13, 26-27). Más aún, en dicho sincretismo estético se daría además una mezcla desproporcionada en la que la preeminencia del texto sobre la música tendría como resultado el relevo de la obra de arte propiamente tal por el fetiche de la mercancía: "La permanente contemporización (Vergegenwärtigung) que la música debe consumar en el poema a costa del tiempo musical persigue el fin de (...) transferir a la apariencia (Schein) de una pura actualidad subjetiva todo lo rígidamente objetivo del poema y con ello el reflejo de un mundo de las mercancías en la obra de arte" (Adorno 1997: t. 13, 94)

En este preciso respecto, es posible afirmar que en su obra tardía Nietzsche lleva a cabo un tipo de análisis estético-político en el que el proyecto wagneriano es interpretado desde las claves sintomáticas del advenimiento del nihilismo europeo. 
Desde una perspectiva técnicamente estética, me parece que se puede contextualizar la crítica nietzscheana aludiendo a aquello que luego se ha denominado Bühnenmusik (Wirth 1986) y que caracteriza a los diversos modos en que la producción musical se encuentra al servicio de diferentes maneras de la representación escénica. Se percibe con cierta facilidad que ya la mera noción de Bühnenmusik implica una inestabilidad inherente al concepto de obra de arte total, desmintiendo así la autenticidad de una composición equilibrada de las artes que la constituyen y mostrando más bien el ordenamiento jerárquico encabezado por la primacía del “mensaje” y su recepción por sobre la poiesis misma. El texto del Nachschrift del Caso Wagner describe este desequilibrio mediante el neologismo Theatrokratie -expresión acuñada tempranamente en 1874 con ocasión de una caracterización del arte wagneriano (cf. texto del Nachlaß en KSA 7, 775)- cuando luego de señalar la arrogancia y el diletantismo de Wagner y sus seguidores declara “...y lo peor: la teatrocracia-, el desvarío de la creencia en la preeminencia del teatro, en el derecho del teatro a detentar la soberanía sobre las artes, sobre el arte” (KSA 6, 42). La inminente consecuencia política de este poder estético se refleja en el segundo de los neologismos usados en este pasaje - Demolatrie-, afirmando que "el teatro es una forma de la demolatría en asuntos de gusto, el teatro es una sublevación de las masas, un plebiscito contra el buen gusto..." (KSA 6, 42). De esta manera, Nietzsche parece adivinar lo que será la proyección de la industria cultural y su adulación de las masas, especialmente en lo que atañe al wagnerismo del siglo XX y su lúcida interpretación llevada a cabo por Adorno dentro de los márgenes de la caracterización del fascismo. Uno de los más representativos fragmentos de la historia del nihilismo contenidos en el Nachlaß (cf. KSA 12, 125-127) advierte justamente sobre el hecho de que la música de Wagner y, especialmente, el final de los Nibelungos, deben ser entendidos premonitoriamente, es decir, como la "preparación del nihilismo (Vorbereitung des Nihilismus)".

Pero también se constata que esta crítica se vuelve muchísimo más compleja cuando se observa que ella se desarrolla en la obra tardía en el contexto más específico de lo que Nietzsche ha llamado das Problem der décadence (KSA 6, 11 y ss., especialmente el $\S 5$ de Der Fall Wagner) y que se apresura en aclarar explicando que no se trata de una cuestión que él, el filósofo y no el moralista, divise desde fuera de la temporalidad epocal así caracterizada o desde un privilegio de pureza con respecto al problema y sus arduas consecuencias en el ámbito del arte. Por el contrario, el texto afirma que también el propio autor del Caso Wagner es un hijo de su tiempo y comparte con el artista el ser inevitablemente un décadent. Esta declaración será de máxima importancia y requiere de un tratamiento autónomo, pues el Problem der décadence manifiesta precisamente uno de los síntomas más incontrastables del advenimiento del nihilismo y su cuestionamiento constituye un punto central en el desarrollo de lo que se denomina filosofía del nihilismo europeo.

\section{OBRAS CITADAS}

\section{Fuentes primarias}

Wagner, Richard. 1963 [1870-1880]. Mein Leben. Martin Gregor-Dellin (ed.). München: List. . 1911. Sämtliche Schriften und Dichtungen. Tomos 1-16. Leipzig: Breitkopf \& Härtel. 
Nietzsche, Friedrich. 1988. Kritische Studienausgabe (=KSA). Giorgio Colli y Mazzino Montinari (eds.). (15 volúmenes). Berlín/New-York: DTV/de Gruyter.

2. Fuentes secundarias

Adorno, Theodor. 1997. Gesammelte Schriften (20 volúmenes). Rolf Tiedemann (ed.). Berlín: Suhrkamp Verlag.

Baudelaire, Ch. 1923. Oeuvres Complètes. F. F. Gautier (ed.). Paris: Nouvelle revue française.

Bermbach, Udo. 2004. Der Wahn des Gesamtkunstwerks. Richard Wagners politischästhetische Utopie. 2004. Stuttgar: Metzler Verlag.

Berlioz, Hector. 1843. Grand Traité d'instrumentation et d'orchestration moderne. Paris: Schonenberger.

Borchmeyer, Dieter y Jörg Salaquarda. 1994. Nietzsche und Wagner. Stationen einer epochalen Begegnung I. Leipzig/Frankfurt am Main: Insel.

Carr, Jonathan. 2007. The Wagner Cltan. Turner 2009.

Janz, Curt Paul. 1978. Friedrich Nietzsche. Eine Biographie I-III. DTV-Wissenschaft.

Köhler, Rafael. 1996. "Natur und Geist. Energetische Form in der Musiktheorie". Beihefte für Musikwissenschaft 37.

Mann, Thomas. 1933. Leiden und Größe Richard Wagners. Im Schatten Wagners. Thomas Mann über Richard Wagner. Editado por Hans Rudolf Vaget Fischer Verlag 2005.

Nilges, Yvonne: Richard Wagners Shakespeare, 2007 Königshausen \& Neumann, Würzburg.

Panagl, Oswald: Die griegische Antike im Spiegel von Selbstzeugnissen Richards Wagner: Mein Leben und die Cosima-Tagebücher. En: Ulrich Müller/ Oswald Panagl Ring und Gral 2002 Königshausen \& Neumann, Würzburg, p. 129 y ss.

Reckow, Fritz. 1977. "Richard Wagner und der esprit d'observation et d'analyse. Zur Charakteristik aufgeklärter Operntheorie”. Archiv für Musikwissenschaft 34: 237-259.

Stollberg, Arne. 2006. "Ohr und Auge - Klang und Form. Facetten einer musikästhetischen Dichotomie bei Johann Gottfried Herder, Richard Wagner und Franz Schreker”. Beihefte für Musikwissenschaft 58.s

Wirth, Heltmut. 1986. "Bühnenmusik”. Musik in Geschichte und Gegenwart. Tomo II. Kassel: Bärenreiter-Verlag. 431-447.

Žmegač, Viktor. 2001. Geschichte der deutschen Literatur vom 18. Jahrhundert bis zur Gegenwart I/1. Konigstein/Ts: Athenaum-Verlag. 